\title{
ON BOUNDS OF MATRIX EIGENVALUES
}

\author{
JINHAI CHEN
}

Abstract. In this paper, we give the estimates both of upper and lower bound of eigenvalues of a simple matrix. The estimates are shaper than the known results.

Mathematics subject classification (2000): 15A18, 15A60.

Key words and phrases: Trace, Rank, Eigenvalue.

\section{REFERENCES}

[1] O. AXelsson, Iterative Solution Methods, Cambridge University Press, Cambridge, 1994.

[2] G. H. Golub AND C. F. VAN LOAN, Matrix Computations, 3rd Edition, The Johns Hopkins University Press, Baltimore and London, 1996.

[3] A. GREENBAUM, Iterative Methods for Solving Linear Systems, SIAM, Philadelphia, PA, 1997.

[4] R. KRess, H. L. DE VRIES AND R. WegmanN, On nonnormal matrices, Linear Algebra Appl., 8(1974) 109-120.

[5] J. W. Liang, Distribution of matrix eigenvalue and its application in numerical analysis, J. Uni. Petrol, 25 (2001), 113-116.

[6] R. S. VARGA, Matrix Iterative Analysis, Prentice-Hall, Englewood Cliffs, N.J., 1962.

[7] H. WOLKOWICZ AND G. P. H. STYAN, More bounds for eigenvalues using traces, Linear Algebra Appl., 31(1980) 1-17.

[8] H. Wolkowicz AND G. P. H. STYAN, Bounds for eigenvalues using traces, Linear Algebra Appl., 29(1980) 471-506. 